\title{
中国西部干旱地区啮齿动物多样性分布格局
}

\author{
周立志 ${ }^{123}$ 马 勇 $^{1 *}$ \\ 1 (中国科学院动物研究所, 北京 100080 ) \\ 2 (安徽大学生命科学学院, 合肥 230039) \\ 3 ( 淮北煤炭师范学院生物系, 安徽淮北 235000)
}

摘要: 在系统整理我国西部干旱地区啮齿动物的分布资料,获得物种分布范围的基础上, 应用 GIS 软件,基于等面 积棚格系统, 研究啮齿动物的等级多样性, 探讨啮齿动物物种的区域分化特征。结果表明, 祁连山地和北塔山、伊 犁天山、阿拉套山和阿尔泰山地, 以及贺兰山地等处的啮齿动物的属数最高 塔里木盆地中心和藏北高原的属数最 低。阿尔泰山南麓、伊犁天山和东祁连山地的啮齿动物科数最多; 塔里木盆地中心和藏北高原的科数较少。在青 藏高原的周边, 寒漠与温性荒漠、荒漠与山地、高原与盆地、荒漠与草原、山地与草原等景观的交界处,多样性指数 较高。蒙新荒漠区的啮齿动物的属科数比相对较高, 青藏高原的属科数比值较低, 但青藏高原的种属数比值相对 较高, 而且 $G-F$ 指数亦较高。

关键词 : 啮齿动物, 生物多样性, 分布格局, GIS ,中国西部干旱地区

中图分类号:Q958 文献标识码：A 文章编号 : 1005-0094(2002)01-0044-05

\section{Distribution patterns of rodent diversity in arid regions of West China}

ZHOU Li-Zhi ${ }^{1,3}$, MA Yong ${ }^{1 *}$

1 Institute of Zoology, Chinese Academy of Sciences, Beijing 100080

2 School of Life Science, Anhui University , Hefei 230039

3 Department of Biology , Huaibei Coal Industry Teachers' College , Huaibei 235000

Abstract : The arid regions of China include Mongolian-Xinjiang warm-temperate arid region and Qinghai-Xizang frigid arid region, located in western China , host 120 species of small mammals including Largomorpha and Rodentia. We collected all of the available distributional data for these species in these regions. Based on GIS models of species range which were predicted by a wildlife-habitat model, we researched the distribution patterns of rodent diversity there. A total of 766 equal-area quadrangle grids that each had an area of 6,470 square kilometers were used as geographic units to collect distributional data of the species, supported by MapInfo Professional Version 4.0. Based on these grid data we obtained the number of genera and families, and calculated the small mammal species diversity of genera and families by Shannon-Winner index and $G-F$ index. In order to explain the species differentiation tendency of small mammals, we introduced number ratios of species to genera and of genera to families as differentiation indices. The results indicate that more genera occurred in mountains around the Junggar Basin, Qilian Mountains , Helan Mountains and the west slopes of Da Hinggan Mountains, where species richness was higher, as might be explained by an edge effect. In contrast, richness was least on the Ordos Plateau and Zhangbei Plateau. There were more families on the south slopes of the Altay Mountains, Tianshan Mountains of Ili and East Qilian Mountains, but fewer on the Ordos Plateau and Zhangbei Plateau. High species diversity often occurred in ecotones such as those among or between frigid desert and warm-temperate desert, desert and mountains, plateaus and basins, desert and steppes, and mountains and steppes. In the Qinghai-Xizang Plateau, number ratios of genera to families were much lower than in the 
Mongolian-Xinjiang region. In contrast, , there were higher ratios of species to genera in the former region. The $G-F$ index was higher in Qinghai-Xizang Plateau, where a great species differentiation was implied. Since small mammals can be used as indicators of biodiversity, the distributional patterns of their species diversity could be helpful for assessment of biodiversity in arid regions of West China.

Key words : Largomorpha and Rodentia , biodiversity, distribution patterns, GIS , arid regions of West China

随着我国西部大开发战略实施，西部地区的生 态环境问题更加受到重视。西部干旱地区由于自然 环境条件十分严酷,生态系统十分脆弱,因此,研究 西部干旱地区的生物多样性具有十分重要的意义。 啮齿动物 (包括兔形目和啮齿目) 对干旱地区自然 环境具有较强的适应能力, 是这一景观中分布广、种 类较多的小型兽类，它们不仅是作为重要的初级消 费者,在干旱生态系统中具有十分重要的地位，而 且, 还可作为生物多样性的指示类群 (Scott et al. , ,Noss ,1990) ,对于研究干旱地区生物多 样性分布规律具有积极的意义。

有关我国西部干旱区啮齿动物区系的研究较 多,但系统地研究物种多样性分布规律的较少 (马 勇，李思华，1981; 赵肯堂，1981; 冯祚建等,1986; ; 国科学院西北高原生物研究所, 1989;王香亭, 1990， 1991 ;王廷正, 许文贤,1992)。以往在研究生物多样 性时, 往往基于群落的个体数目; 研究生态多样性, 即区域性的生物多样性研究, 则强调景观区域之间 的物种组成差异，以及不同区域的物种丰富度格局 (纪维红,陈服官,1990;Davis et al. 1990;Scott et al. 1993 ; Zhou et al. ,2000 ${ }^{1}$; 周立志等 2001) , 即 侧重于物种多样性的横向比较。由于生态多样性适 于较短时间尺度上的生物群落研究, 蒋志刚等 (蒋 志刚，纪力强，1999) 提出了基于 $G$ 指数与 $F$ 指数测 度较长时间内一个地区的生物多样性, 对于研究时 间序列上的物种多样性具有积极的意义。本文借助 等积棚格系统的地理分布单元, 基于物种数目, 分别 采用 Shannon-Wiener 指数 (Molles，1999) 和 $G-F$ 指 数测度我国西部干旱地区的啮齿动物多样性, 进行 生物多样性时空格局研究, 探讨物种区域分化特征。

\section{1 自然概况}

我国西部干旱地区是指西北干旱区及青藏高原 干旱和半干旱区 (中国科学院《中国自然地理》编辑 委员会 ,1985)，包括温旱和寒旱两种自然景观类
型，其面积占国土总面积的一半以上,地理范围为 $73^{\circ} 40^{\prime} \sim 123^{\circ} 40^{\prime} \mathrm{E}, 28^{\circ} \sim 50^{\circ} \mathrm{N}$ 。

西北干旱区是欧亚大陆的草原与荒漠的一部 分,气候极为干旱, 年降水量较少, 蒸散量大, 日较差 大。植被自东向西, 由草原逐渐变为半荒漠和荒漠。 区域内有大片的戈壁和流动、半流动沙丘覆盖的沙 漠, 在中山带有草原和森林。青藏高原是一个独特 的地理区域, 为海拔最高的高原, 平均海拔高度在 $4500 \mathrm{~m}$ 以上, 空气稀薄, 年平均气温在 $0^{\circ} \mathrm{C}$ 以下; 植 被以高寒荒漠类型为主。

\section{2 研究方法}

\section{1 物种分布资料的整理}

啮齿动物 (包括兔形目和啮齿目) 地理分布资 料来源于中国科学院动物研究所标本馆馆藏和有关 单位收藏的标本, 以及国内外有关文献和资料。通 过对物种地理分布及栖息环境的系统整理, 建立中 国西部干旱地区啮齿动物地理分布数据库。运用 GIS ( MapInfo Professional Version 4.0) 软件, 根据啮 齿动物地理分布数据库和中国科学院地理研究所开 发研制的中国资源环境数据 (1:4000000) ,结合啮 齿动物的栖息特点，进行生境分析，对 20 世纪 50 年 代以后的分布记录点进行确认, 获得相对准确的地 理分布资料。根据确认的分布点, 运用 GIS 软件, 通 过建立野生动物物种 - 生境模型, 获得物种的分布 区图 (周立志等, 2000)。

\section{2 物种分布数据的处理}

为了确保和地理单元数据的可比性, 以 766 个 等面积栅格 $(80.43 \mathrm{~km} \times 80.43 \mathrm{~km})$ 单元统计物种 分布数目。本文基于地理分布单元区内的啮齿动物 物种数目，按 Shannon-Wiener 指数 (Molles, 1999) 分 别计算各地理单元科和属的物种分布多样性。考虑

(1) Zhou L Z , Y Ma and X D Ye 2000. Species richness of glires in relation to environmental factors in arid regions of China. Proceedings to Third Sino-Russian Symposium on Animal Diversity and Regional Sustainable Development. Urumqi , September $18 \sim 20,122 \sim 132$ 
到分类的等级特征, 即属 $(G)$ 和科 $(F)$ 的等级多样 性 $\left(H^{\prime}\right)$, 则, $H^{\prime}=H^{\prime}(G)+H^{\prime}(F)$, 其中, $H^{\prime}=-\sum p_{i} \lg p_{i} p_{i}$ 为某一属或科在一个栅格内出现 的物种数占所有棚格内该属或科的总物种数的百分 比; 采用 $G-F$ 指数测度地理单元内的物种多样性， 衡量属与科水平上的物种多样性变化趋势, $G-F$ 指 数的应用引自蒋志刚 (1999) 的文献; 为了探讨我国 干旱地区啮齿动物的历史发展趋势，定义栅格内的 物种数 $(N s p)$ 与属数 $(N g)$ 以及属数 $(N g)$ 与科数 $(N f)$ 之比为分化指数, 则物种分化指数 $D s p=N s p$ ／ $N g$,属的分化指数 $D g=N g / N f$ 。

\section{3 结果}

\section{1 我国西部干旱地区啮齿动物物种组成}

分布于我国西部干旱地区的啮齿动物共有 120 种，物种组成见表 1 。

\section{2 我国西部干旱地区啮齿动物科属的分布格局} 准噶尔盆地周围的天山山地、阿拉套山地和阿 尔泰山地，祁连山地和北塔山，阿拉善荒漠东缘，锡 林郭勒高原的东、南缘等地的啮齿动物属的分布数 量较高 (17 属以上), 其中，以祁连山地和北塔山，伊 犁天山、阿拉套山和阿尔泰山地，以及贺兰山地等处 的属数最高 (20 属以上) 塔里木盆地中心和藏北高 原的属数最低, 都不超过 6 属 (图版 I, 图 1)。阿尔 泰山地、准噶尔界山山地、天山山地、昆仑山 - 阿尔 金山 - 祁连山地、喜马拉雅山脉南麓、内蒙古高原东 部、大兴安岭的西及南麓、鄂尔多斯高原和张北高原 分布的啮齿动物的科数目相对较多，其中，以阿尔泰 山南麓、伊犁天山和东祁连山地的科数最多塔里木 盆地中心和藏北高原的科数较少, 不超过 4 科 (图 版 I , 图 2)。

\section{3 我国西部干旱地区啮齿动物多样性}

基于物种数目的物种地理分布多样性格局 (图
版 II ,图 3 ) 表明, 在青藏高原的周边, 寒漠与温性荒 漠、荒漠与山地、高原与盆地、荒漠与草原、山地与草 原等景观的交界处，多样性指数往往较高。

\section{4 我国西部干旱地区啮齿动物分化趋势}

若以下一阶元的分类单元数与上一阶元的分类 单元数的比值来量化各棚格中啮齿动物的分化趋 势，则可看出我国干旱地区啮齿动物分化的一般趋 势, 蒙新荒漠区的啮齿动物的属科数比值相对较高, 青藏高原的属科数比值较低, 但青藏高原的种属数 比值相对较高(图版 II III, 图 4 5)。

青藏高原、天山山地和阿尔泰山地啮齿动物的 $G-F$ 指数较高, 尤其以青藏高原最为明显(图版 III, 图 6)。

因此，在科级水平的分化上，蒙新荒漠区的分化 程度相对较高; 在属级水平分化上, 青藏高原区及蒙 新荒漠区西北部和中部的分化程度相对较高; 而 $G$ $F$ 指数则综合科和属的分化, 表现为青藏高原区的 分化程度相对较高。

\section{4 结论}

动物地理分布的多样性格局是动物在长期进化 过程中与自然环境相适应的结果。小型兽类的迁移 性小, 与生境关系密切, 是较好的生物多样性指示类 群，我国啮齿动物的物种分类和分布状况的研究比 较系统和全面，因此，可以利用啮齿动物来测度区域 的物种多样性。

从我国干旱地区的啮齿动物多样性分布格局来 看, 准噶尔盆地四周的天山山地、阿尔泰山地, 东祁 连山地以及内蒙古东部的荒漠与草原交错带的啮齿 动物多样性程度较高, 而各大盆地的沙漠中心以及 寒漠腹地啮齿动物多样性较低,由此可以预测这些 地区相应的生物多样性水平。

我国干旱地区啮齿动物物种多样性的空间分布

表 1 我国西部干旱地区啮齿动物物种组成

Table 1 Species component of rodents in arid regions of West China

\begin{tabular}{|c|c|c|c|c|c|c|c|c|c|c|c|}
\hline \multicolumn{2}{|c|}{$\begin{array}{c}\text { 兔形目物种数 } \\
\text { Species number of } \\
\text { Largomorpha }\end{array}$} & \multicolumn{9}{|c|}{$\begin{array}{c}\text { 啮齿目物种数 } \\
\text { Species number of Rodentia }\end{array}$} & \multirow{2}{*}{$\begin{array}{c}\text { 物种总数 } \\
\text { Total of } \\
\text { species }\end{array}$} \\
\hline $\begin{array}{c}\text { 免科 } \\
\text { Leporidae }\end{array}$ & $\begin{array}{l}\text { 鼠兔科 } \\
\text { Ochotona }\end{array}$ & $\begin{array}{l}\text { 松鼠科 } \\
\text { Sciuridae }\end{array}$ & $\begin{array}{c}\text { 鼠吾鼠科 } \\
\text { Petauristidae }\end{array}$ & $\begin{array}{c}\text { 河狸科 } \\
\text { Castoridae }\end{array}$ & $\begin{array}{c}\text { 仓鼠科 } \\
\text { Cricetinae }\end{array}$ & $\begin{array}{c}\text { 鼠科 } \\
\text { Muridae }\end{array}$ & $\begin{array}{l}\text { 睡鼠科 } \\
\text { Gliridae }\end{array}$ & $\begin{array}{l}\text { 林跳鼠科 } \\
\text { Zapodidae }\end{array}$ & $\begin{array}{l}\text { 跳鼠科 } \\
\text { Dipodidae }\end{array}$ & $\begin{array}{c}\text { 豪猪科 } \\
\text { Hystricidae }\end{array}$ & \\
\hline 4 & 17 & 11 & 3 & 1 & 56 & 12 & 1 & 3 & 11 & 1 & 120 \\
\hline
\end{tabular}


格局表明,在干旱区的景观交错地带,如祁连山地、 阴山 - 贺兰山地, 以及干旱地区的边缘地带如大兴 安岭西簏、阿尔泰山南簏、天山北簏、喜马拉雅山脉 南簏的物种多样性相对较高。这些物种较为丰富的 地区实际上是不同群落相联结的区域,生态学上称 为群落交错带, 它是一个过渡地带。群落交错区物 种数量增加的现象，生态学上称为边缘效应( 孙儒 泳,1992)。祁连山地地处阿拉善荒漠、青藏高原、 黄土高原之间，是温性荒漠带、高寒荒漠带和荒漠草 原带的交界处，交错区的环境条件明显与其核心区 域不同。该处不仅植被类型多样,地貌类型较为复 杂，而且降水量相对较高，具有上述三种景观的过渡 特征,各种景观的物种如喜湿、耐旱种类都可出现在 此处，因此物种丰富度较高。在阴山 - 贺兰山地，以 及干旱地区的一些边缘地带，如大兴安岭西簏、阿尔 泰山南麓、天山北簏、喜马拉雅山脉南簏都有相似的 现象。因此, 这种边缘效应在我国干旱地区是较为 普遍的。而在寒漠的中心如藏北高原,温性荒漠的 中心如塔克拉玛干沙漠和阿拉善沙漠, 生境则极为 单调, 物种数量极少。

从我国干旱地区的地形来看,东部和东南部受 季风气候影响，降水量较高，西部受大西洋冷湿气流 影响, 降水量亦相对较高, 而青藏高原作为南部高大 的屏障,阻挡了印度洋暖湿气流, 使得高原腹地和蒙 新西部降水量甚少,使我国西部呈中部干旱、西北和 东南相对较湿润的气候格局。虽然我国干旱地区啮 齿动物向耐旱方向特化,干旱地区特有种占总特有 种数的 $56.3 \%$ (周立志，马勇，1999），但在干旱环境 中，水分仍然是动物分布的关键因子之一 ${ }^{\mathbb{1}}$ 。水分 可以通过植被土壤等因素对动物的分布起作用。因 此, 自然因素无疑对生物多样性格局的形成起决定 性的作用。

种、属、科等分类水平上的多样性格局只能体现 特定区域目前的动物区系分布现状，但是通过动物 分类阶元的纵向比较,不难确定一些重要的分化区 域。以往在研究动物物种分化时, 往往根据物种丰 富度来确定物种的分化中心 (张荣祖, 1999) ,但考 虑到物种水平的动物多样性是最低层次的多样性， 体现在研究区系演变过程中动物与生存环境的最近 的适应关系时, 要推测其发展历程, 必须结合种上阶 元的多样性。通过分析我国西部干旱地区啮齿动物 种与属以及属与科的数目的比值，我们对该区域的
区系演变过程有了一个初步的认识。从多样性指 数、属和科的多样性来看, 我国西部干旱地区中, 蒙 新干旱区的啮齿动物各分类等级的多样性都较高， 准噶尔周围山地、东祁连山地似乎是物种分化的关 键地区, 但如果考虑各分类阶元之间的纵向联系, 即 考虑区系演变的时间格局, 那么情况就有所不同了。 图 4 给出的种属数目的比值显示了青藏高原的啮齿 类在属的物种分化程度较大, 而图 5 给出的属科之 比表明蒙新地区的啮齿类在属级阶元内的分化程度 较大( 见图版 II, III)。考虑到动物区系演化过程 中, 属级分化的时间要早于物种分化, 因而从一个侧 面反映了青藏高原隆起后所引起的地理环境变化导 致了动物区系的巨大变化( 陈宜瑜等, 1996)。但分 化的程度高并不代表那里的物种多样性程度高, 因 为, 物种的分布与环境条件是密切相关的。物种分 化水平高与青藏高原特有种较多的现象是相吻合 的。G-F 指数体现时间序列中种上分类阶元的物种 多样性 (蒋志刚, 纪力强, 1999) , 图 6 给出的 $G-F$ 指 数体现了青藏高原的啮齿动物的种上阶元物种多样 性在时间序列上的区系演变特点 (见图版 III)。

青藏高原是在第三纪上新世末和第四纪初开始 隆升 (李吉均等, 1979), 亚洲中部地区的一些山脉 也是在第四纪初开始再次抬升（马勇，李思华， $1981 ）$ 加上第四纪的冰川作用，使这些地区的地理 环境发生了巨大的变化, 环境条件的巨大变化是物 种分化的动力。可以认为, 青藏高原在我国西部干 旱地区动物区系演化过程中是物种分化的重要区域 之一。

\section{参考文献}

陈宜瑜, 陈毅峰, 刘焕章, 1996. 青藏高原动物地理区的地位 及东部界线问题. 水生生物学报, $20(2): 98 \sim 103$

冯祚建, 蔡桂全, 郑昌琳, 1986. 西藏哺乳类. 北京: 科学出版 社, $255 \sim 396$

纪维红, 陈服官, 1990. 翼手目物种密度分布与环境因素的 关系. 兽类学报, $10(1): 23 \sim 30$

蒋志刚, 纪力强, 1999. 鸟兽物种多样性测度的 $G-F$ 指数方 法. 生物多样性, 7(3): 220 225

李吉均, 文世宣, 张青松, 王富葆, 郑本兴, 李炳元, 1979. 青 藏高原隆起的时代、幅度和形式的探讨. 中国科学,

(1) Zhou L Z , Y Ma and X D Ye 2000. Species richness of glires in relation to environmental factors in arid regions of China. Proceedings to Third Sino-Russian Symposium on Animal Diversity and Regional Sustainable Development. Urumqi , September $18 \sim 20,122 \sim 132$ 


\section{(6) : $608 \sim 616$}

马勇, 李思华, 1981. 新疆北部地区啮齿动物地理分布的研 究. 动物学报, 27(2): 180 188

孙儒泳, 1992. 动物生态学原理. 北京: 北京师范大学出版 社, 329, $360 \sim 361$

王香亭, 1990. 宁夏脊椎动物志. 银川: 宁夏人民出版社, 605 $\sim 692$

王香亭, 1991. 甘肃脊椎动物志. 兰州: 甘肃科学技术出版 社, $1001 \sim 1127$

王廷正, 许文贤, 1992. 陕西啮齿动物志. 西安: 陕西师范大 学出版社, $62 \sim 260$

赵肯堂, 1981. 内蒙古啮齿动物. 呼和浩特: 内蒙古人民出版 社, $33 \sim 225$

张荣祖, 1999. 中国动物地理. 北京: 科学出版社, 221

中国科学院《中国自然地理》编辑委员会, 1985. 中国自然地 理总论. 北京: 科学出版社, $133 \sim 164,187 \sim 413$

中国科学院西北高原生物研究所, 1989. 青海经济动物志. 西宁: 青海人民出版社, 659 728

周立志, 马勇, 1999. 中国干旱区啮齿动物多样性. 淮北煤师 院学报(自然科学版), 20(2): 46 52
周立志, 马勇, 李迪强, 2000. 大沙鼠在中国的分布. 动物学 报, 46(2): $130 \sim 137$

周立志, 马勇, 李迪强, 2001. 沙鼠亚科物种空间分布格局及 其与环境因素的关系. 动物学报, 47(6) : 616 624

Davis F W, D M Stoms, J E Estes and J Scepan, 1990. An information system approach to the preservation of biological diversity. International Journal of Geographical Information Systems, 4(1): $55 \sim 78$

Molles M C Jr., 1999. Ecology: Concepts and Applications. Science Press, Beijing (Authorized reprinting), 306

Noss R F, 1990. Indicators for monitoring biodiversity: a hierarchical approach. Conservation Biology, 4(4) : $355 \sim 364$

Scott J M, F Davis, B Csuti, R Noss, B Butterfield, C Groves, H Anderson, S Caicco, F D erchia, T C Edwards Jr., J Ulliman and R G Wright, 1993. Gap analysis: a geographical approach to protection of biological diversity. Wildlife Monographs, 123: $1 \sim 41$

Scott J M, B C James, D Jacobi and J E Estes, 1987. Species richness: a geographical approach to protecting biological diversity. BioScience, 37 (11): $782 \sim 788$

(责任编辑 : 问文杰)

2001 年第 9 卷第 4 期第 376 页,由于排版的失误, 本刊将肖治术先生文章中 的图 2、图 3 的内容颠倒, 特此更正, 并向作者致歉。 